\title{
Under the Shadow of Time: Where Indicators and Academic Values Meet
}

\author{
ULRIKE FELT \\ UNIVERSITY OF VIENNA
}

\begin{abstract}
This essay aims at relating the growth of indicators to the shifting temporalities of academic work. Drawing on research into academic work and lives but also on professional experiences, I develop the notion of chronopolitics to analyze the politics of time governing academic knowledge production, work and evaluation. Drawing on a range of examples, from the projectification of academic work and lives to the epistemic effects of strictly timed career structures, I point to the multiplication of theatres of accountability and to the shifting focus of academic work from a logic of discovery to one of delivery. In conclusion, I suggest moving beyond a debate of how to best play the indicator game, to a more fundamental critique of the entanglement of indicators and time, and to a re-timing of research as a political project.
\end{abstract}

\section{Keywords}

chronopolitics; indicators; accountability; metrics; academic work

\section{Introduction}

The critical discussion of the growing density of assessment structures in academia, including the introduction of an ever-expanding set of indicators deployed to evaluate the quality of delivery as well as the use of rankings as a means of orientation, has been around for quite some time (e.g., Espeland and Sauder 2007, Fochler and de Rijcke 2017). Analysts, researchers, and even policy makers have highlighted the potentially detrimental effects of the multiple quantifications and standardizations that have been woven into research processes (e.g., the DORA declaration highlights the problematic nature of the impact factor") and have pointed at the "tyranny of transparency" (Strathern 2000) supported by indicators. They have expressed concerns that this might limit our future capacity to innovate in ways that fit broader societal values. Moreover, we can identify at least partial agreement on some of the highly problematic and unacknowledged "collateral realities" (Law 2011) that these types of interventions into the research system produce for both academic work and life.

. Ulrike Felt, Email: ulrike.felt@univie.ac.at

¿See: http: / / www.ascb.org/dora/

Copyright (C) 2017 (Ulrike Felt). Licensed under the Creative Commons Attribution Non-commercial No Derivatives (bync-nd). Available at estsjournal.org. 
From an STS perspective, and as a researcher affected in many different ways by the spread and use of indicators, it seems essential to move beyond both diagnosing the "indicator problem" and sharing work-arounds and skillfully negotiated micro-solutions. Rather, it seems much more promising to question the robustness of such indicator-driven environments and to investigate how they are maintained despite this sustained critique. We could start by reflecting on the "trust in numbers" (Porter 1995) omnipresent in contemporary societies. Numbers, and the ways they change over time, have actually become essential for how we grasp the world around us, how we assess its development and how, ultimately, we care for it. This, in turn, finds its expression in the core value of accountability and the audit structures put into place (Power 1999), which are the backbone of the (new public) management ideology that seems to have taken firm hold of the academic world (e.g., Amaral, Bleiklie, and Musselin 2008).

While these are certainly important elements of any explanatory narrative on current transformations in academia, I would like to point to and engage with a largely invisible, takenfor-granted, and thus unquestioned perspective: that of academic chronopolitics ${ }^{3}$ and its relation to indicators. Chronopolitics refers to the politics of time governing academic knowledge generation, epistemic entities, and academic lives and careers, as well as academic management processes more broadly speaking. In my contribution to the indicator debate, I therefore want to argue that major temporal reorderings within academia stand in a coproductive relationship with the growing number of indicator systems, both preparing the ground for and stabilizing the reconfiguration of broader academic regimes of valuation through a specific set of indicators. Therefore, the tempor(e)alities of academia, i.e. the different temporal regimes and the lived realities they bring about, cannot be disentangled from indicators, and both need to be questioned together.

The following reflections are based on my work as an analyst of changes in institutions of higher education. Yet, they are also nourished by different types of professional experiences: as Dean of a major Faculty of Social Sciences at an Austrian university, as a professor in STS having built a department that is assessed on a regular basis, as an academic whose quality is scrutinized in many different ways and who asks the "quality question" in multiple peer evaluation contexts, and finally, as a supervisor and mentor of numerous young scholars.

\section{Chronopolitics and Indicators}

Recently, the close relations between contemporary expectations of academic productivity and the introduction of new temporal regimes of governance have begun to be subjected to critical scrutiny (e.g., Gibbs et al. 2015, Felt 2009, Ylijoki and Mäntyla 2003, Felt 2016). Analyses collectively point to the emergence of a dense infrastructure of multiple temporalities that frame both knowledge and agency in academia. This happens against the backdrop of a number of concerns: diagnostic narratives circulate, voicing doubts about whether universities are still capable of performing "up to their time" (zeitgemäß) in educating the next generation of

${ }_{3}^{3}$ For a good reading on current debates in chronopolitics see Klinke (2013). 
knowledge workers, and ensuring the steady flow of innovations. Universities as key academic institutions are questioned concerning their "future-ability" (zukunftsfähig), i.e., their capacity to both adapt to and participate in the production of specific societal futures. Policy makers and some stakeholders from the economic sector voice concerns about whether universities are prepared for and capable of competing for a place in the global race, as well as whether they can sufficiently embrace the ideals of speed and efficiency.

Indeed, whenever a major problem in the academic system was identified, it often led to the introduction of a new temporal regime as well as indicator(s), which would define and allow the measurement of what should be achieved. This move was supposed to lead to better (self-) control, more transparency and efficiency, and improved manageability of the research system. Over the past decades we have witnessed the introduction of several new temporal structures into academic research. I present three concrete and highly visible examples that have reshaped academic lives in Austria and well beyond. First, a quasi-exclusive organization of research through third-party funded projects—often labeled as projectification-has been implemented to ensure a competitive distribution of financial resources to the research system. At my university, research without third-party funding is now virtually impossible, and the acquisition of projects has become a key indicator of the success of a university, a faculty, a discipline or an individual researcher (e.g., in my faculty tenure is not granted without the candidate having shown his willingness to compete for highly competitive third-party funding). This has an impact on several levels. Knowledge production must now be packaged in (generally) three-year units, and publications are required during this time-span to demonstrate the worth of the investment. The contracts of those hired for projects (mostly $\mathrm{PhD}$ students) are also temporalized along this logic. I have observed a clear shift-particularly in project-intensive environments in the social sciences-from publishing books to writing articles. The latter are seen to be a better fit with the temporal and counting logic of funding agencies and universities, and to offer a more immediate short-term return on investment. Particularly for the newly emerging and quite large group of time-limited contract researchers the new metric imagination tied to article production seems more attractive: quick validation of their work and access to money for post-doc projects (high-quality publications are a prerequisite for getting this type of funding). This leads to my deep ambivalence as a mentor in an indicator-driven environment: despite the fact that being able to write a monograph seems essential and allows scholars to produce larger narratives, it is also important to communicate the reality that articles are easier to validate in most career-related contexts. However, this is also a problem on a more senior level, as the time required to write books is not easily compatible with the need to acquire ever new projects.

A second example of a new temporal regime is the introduction of rather strictly timed careers aimed at fostering competition among "the best"; this is changing the frequency and the normative framing of the accountability procedures with which researchers must comply. In the framework of these career processes, indicators definitely gain importance, both explicitly and implicitly. In particular, young researchers-out of their deep desire to do everything possible to succeed-gradually embody these indicators through self-auditing processes when seeking orientation. Tenure contracts in the social sciences in my faculty contain precise minimal 
requirements in terms of the number or frequency of articles to be produced in the four year "period of observation" before being able to request tenure. No work-around is possible. In this case, we see a tight coupling of time and specific types of output, with quantitative indicators forming the entry ticket to the qualitative review of academic achievements in tenure processes.

Performance based budgeting is the third example of the re-timing of the research system I live in. It redefines the relation between the state and universities, who must agree on budgets in time intervals of three years: this allocation of funds is largely based on a fixed set of indicators, for which universities must collect data in the framework of the so-called Wissensbilanz (translatable as "knowledge accounting system"). Every single academic must "feed the accounting system" with information concerning his/her third-party funding, publications, talks, outreach activities and many more duties performed during a calendar year. This information is then filtered in context-specific ways, selecting only those elements seen as representing the highest value: third party funding, (S)SCI publications, invited key-notes, number of graduates, etc. These "innocent" practices of collecting and centralizing data lead to the internalization of specific counting and accounting systems by researchers-and here I include myself. These sets of indicators are then often established as equivalent to the collective achievements of any department or faculty in a given year and can be used to observe developmental trajectories over time.

Indeed, these three examples nicely capture how, along with every new time structure, new (combinations of) indicators used to measure performance are also introduced or strengthened. They are supposed to capture the "health of the system" and keep track not only of its development but also of individual and institutional positionings. There is always a specific blend of indicators, including number of publications in top venues, highly cited papers, thirdparty funded projects (with specific attention to so-called "excellence projects"), patents, graduates and many more. Tracking these target numbers is thus imagined as part of an early warning system for potential problems and as the basis of legitimate interventions into a system otherwise imagined as largely autonomous.

A short ethnographic intermezzo to think with
The Dean and the Rector meet annually for the "target agreement negotiations"
(introduced with the new Austrian university law in 2004). Approximately 12 people-
each "side" brings its team - sit around a table for some 3 hours discussing basic budget,
teaching, and infrastructural needs for the upcoming year. The lengthy preparation
document in front of us contains my answers as a Dean to concrete questions the Rector
had posed ahead of the meeting, but above all, it contains extensive tables, which have
been prepared by the central administration and extracted from the Wissensbilanz as well
as other accounting systems (e.g., for teaching hours). Data are presented in time rows
covering the last three years. This should somehow speak for the development of the
Faculty and situate the work of the past year in temporal context. The Rector browses


through the document and shares his comments. In "good years" he would say that the faculty has been doing quite well ... publications ... more international, SSCI, Q1,... very well, continue like that, ... high level of third-party funding, keep level, no increase needed. I then mention, for example, that some achievements did not find their way into the report; I would point out that published books were missing from the detailed output tables and that in some fields they were really important. Some nodding, no numbers to speak for this output. Exchanges continue over other items, always rather short and to the point. Some ranking would be briefly mentioned. It speaks in our favor; well then, ... A lot to discuss in little time. For a moment I am happy that the basic budget is not dependent on these indicators; it mainly builds on staff and student numbers; this seems to provide some relief from being overly concerned with the numbers in the document. Yet, I know, the numbers nevertheless matter greatly: they create the general climate and thus open up or shut down possibilities for negotiating other issues beyond the basic budget; they are important elements in the overall valuation of who "we" are and where "we" stand within this huge institution. Welcome back, dear ambivalence; this time I did not need to tell compensatory narratives about why our indicators did not show what they should have - I realize that for a moment I like "my indicators" as they seem to tell a good story, and, simultaneously, I know about some of their more detrimental effects in such a tightly timed environment.

\section{Multiplying Theatres of Accountability}

This short ethnographic story points to the fact that every new time structure seems to reshape existing, or create new "theatres of accountability" (Marres 2012, 86), and that these theatres reconfigure the "literary, spatial and technical arrangement[s] of publicity." In other words, changing time structures and the new rhythms of accountability they bring with them, chart new territories where and moments when accountability needs to be performed, request us to produce different sets of narratives, put different areas of academic activities in focus and sometimes also demand new techniques of producing evidence for what has been achieved. And above all: they also address different audiences, from the scientific (sub)community, to tenure committees, to deans or university presidents. Certain empirical evidence is on stage, which should speak to a specific set of "spectators," i.e., academic managers, policy makers, or scientists (e.g., target agreements described above are semi-public) on behalf of the work done. And vice versa: every theatre also performs a blend of specific types of temporality. For example, when faculty assessments, departmental assessments and individual assessments are performed, they focus on different timespans and relate to very different imaginations of relevant timeframes and what should be achieved within them. A recent article in the Times Higher Education (Crook 2016), for example, pointed out how the "protracted delay between submitting an article and receiving a decision" can put early career scholars in what she calls a "CV limbo," while it might matter less for the long-term assessments of departments. In the end, once specific theatres become well entrenched they frame the different ways in which we perform time. 
The metaphor of the theatre not only highlights the performative character of indicators, but also draws our attention to the types of stories that can be told on stage about academic endeavors worth undertaking. The more the indicator logic gains power, the more larger storytelling efforts turn out to be difficult to perform and the more attractive rather narrowly confined "short stories" seem to be-we speak about only one year against the backdrop of the two previous ones. Impact factors, to take another example, are often core actors in stories about successful positioning of an individual, a department or an institution. Yet, impact factors themselves incorporate a specific time structure: in any given year the impact factor only reflects the average citation of articles in a given journal in the two preceding years. They thus tell a really short story about the intellectual life of an article and its impact-in particular for the social sciences and humanities. While one might argue that this is different for every scientific (sub)community and therefore should not be and is anyway not compared across knowledge boundaries, it tacitly makes a difference. It demands explanation on the part of those communities who publish in journals with relatively low impact factors. Feeling the need to explain that an impact factor of 3 is really very high for your field of research to a colleague from the natural sciences who aims to publish in $15+$ impact factor journals is without any doubt a sign of tacit and explicit orders in place and of power relations at work.

Departmental evaluations occurring every five years are another theatre of accountability. In addition to the written self-assessment report, where we can try to develop a longer story line (in very few pages), and the numbers that speak for us, we have exactly "50 minutes with peers," during which considerable time is actually spent in appraising what in German would be called the "number scaffold" (Zahlengerüst)—the number of specific performances per category in the last five years.

In both theatres, little to no space is provided for reflecting on investments that did not turn into (ac)countable results, either because they might only produce returns in a long-term perspective (e.g., interdisciplinary collaborations) or because they did not produce any obvious returns, such as project proposals that were not successful (which is, on average, four out of five proposals). Neither theatre of accountability invites experimentation with new forms of representing what we do. Both as a Dean and as head of a Department, to a large degree you play the game, maybe trying to push it a bit beyond the limit or to weave some alternative narratives into your accounts. These remain, however, mostly micro-experiments, e.g., attempts to use the same numbers to tell different stories and thus trying to undermine the dominant way of thinking. Yet, the encounters where negotiations can occur are rare and short. Here, temporal orders definitely help to stabilize the dominant order introduced through the indicator game.

\section{Discovery or Delivery}

When leaving the stages of such theatres, I find myself quite frequently asking what is actually represented by indicators: what "entities" (long-term epistemic interests, specific types of care work, failed project applications, negative results, students not graduating, etc.) do not fit into the imaginary of an indicator-ordered world and why do they not fit? Or, to put it differently: do 
some "entities" not fit because they are problematic in terms of describing the quality of contemporary research and teaching, and is it problematic that they do not fit? And I also ask myself the following: what imaginary of the constant delivery of measurable output is underlying the idea of following a developmental trajectory over time? Numbers seem to allow us to construct trajectories for people, departments and faculties, through measuring incoming/ outgoing flows of third-party funding, papers, talks, etc. The idea that by lining up indicators over time, stability, improvement or decline might be rendered visible is an excellent example of Appadurai's $(2013,223)$ diagnosis of "trajectorism" as a key characteristic of modernity. He underlines that one of the "deeper epistemological and ontological habit(s)" of our time is the omnipresent assumption that we can explain the world-in my case the academic world-through describing it as "a cumulative journey from here to there, more exactly from now to then, in human affairs [...]. Trajectorism is the idea that time's arrow inevitably has a telos, and in that telos are to be found all the significant patterns of change, process and history." To buy into the trajectory logic also suggests that developments can be-if they more or less follow a specific ideal trajectory-considered as being in control.

And finally, I ask myself how I can reflect all of this in my own doings, in my mentoring, in my leadership functions? How should I think about my allocation of time?

Drawing on many interviews with researchers about their lives in contemporary universities, as well as my own experience, I can only agree with Murphy $(2015,142)$ that strongly indicator-driven accountability structures have gradually shifted time allocations from "discovery" to "delivery." The former is devoted to the production of "new knowledge of enduring significance that was published" and was initially imagined as "far removed from administrative forms of organization." The latter allowed for irregular production cycles, with some quite intense moments and other periods of less-visible output. Delivery works in ways that are structurally and temporally different-regularity is expected. In smaller, often interdisciplinary, academic units, such as the STS department I am part of, this question of fluctuation over time in the production of (ac)countable entities remains a regular topic of discussion. We should uphold the rhythm of third-party funded projects without knowing how many applications are needed to assure the constant success rate; we sometimes question the year in which we should count a publication (online first or print) to eliminate large fluctuations; and the number of $\mathrm{PhD}$ and MA graduates should also be on a stable or, ideally, on a slight upward trajectory. This seems particularly important-and is a real challenge-for a field that does not belong to the long-standing disciplinary canon and thus is not stabilized through its reference of "always having been there."

Certainly, part of the time devoted to the work of discovery has been transferred to the work of delivery, to boosting the number of papers at the output end and of projects at the input end. Yet, not only has the time balance changed, so has the entire expectation of discovery: discovery only counts through its deliveries. Thus, we must continually produce something that can be delivered, as everything that does not fit this logic "disappears" in a delivery oriented world. Therefore, the time invested in care and support work of all types does not appear as a "good investment," nor does engagement in complex collaborative work across boundaries, or 
much of the community work that science rests upon; mentoring only becomes visible when the mentee is successful and can be added to the list of "deliverables." Therefore, indicators gradually create blind spots in how we describe ourselves, the institutional entities we are part of, as well as wider systemic developments. We can, of course, still claim that this can be compensated by our capacity to qualitatively acknowledge those elements that are not represented by indicators. Yet such qualitative add-on stories often have a compensatory tone, explaining why indicators do not tell the whole story. As a mentor, I often debate with young scholars how essential it has become to understand the indicator game and to partially play it while never forgetting that it is a game-a game that should not be able to define who they are as intellectuals. Yet, from our research, I also know that the indicator game creates shifts, for example in choices about co-authorship and, more generally, it also contributes to the narrowing of the valuation repertoires of young researchers (Müller 2012, Fochler, Felt, and Müller 2016).

\section{Pleasure and Morality}

Indicators, and the related temporalization of research, are not only oppressive and reductive. The indicator game sometimes also offers moments of empowerment and pleasure. Being happy when one fits, more or less, into the indicator game-the feeling of synchronicity with othersand thus being able to produce a more or less coherent narrative, is something I have experienced in my role as a dean and also as head of my department (see above). This is a deep moment of ambivalence. Not needing extra justification as social sciences vis-à-vis other faculties, or as a small non-classical social science discipline, is a relief. Yet I also know that this actually perpetuates the current system. It enables existing orders to remain in place, as once researchers have long enough successfully played the game, they show a tendency to forget that they saw it as a game in the first place. No longer perceiving it as a game then allows one to see the capital acquired in the indicator game as real currency, as the tangible outcome of accumulated labor, which can be exchanged well beyond the confines of the game (Bourdieu 1984).

Indicators sometimes appear to open up spaces. This can be especially true for academics struggling to come to terms with where they stand in their academic lives and careers. They can accordingly find situated ways to productively work with indicators. Narratives concerning indicators then manage to foreground the pleasure of successfully competing on the level of specific indicators: satisfaction when one wins "chips" in the indicator game, enjoyment when one manages to trick the system, and the feeling of being on the "right track" seemingly without depending on the assessment of others. This becomes visible when academics (both as individual and as heads of departments) start talking about increasing their publications in SSCI ranked journals, when a specific number of SSCI publications (contractually fixed as permitting an application for tenure) is reached or when $\mathrm{PhD}$ candidates ponder whether they should write a monograph type of dissertation or choose-often judged as more rewarding-an article-based thesis. Then, indicators suddenly promise better oversight over one's situation and allow, at least for some, the implementation of a one-step-at-a-time program towards potential success. 
Keeping one's academic life in shape through taking a certain number of smaller steps strongly resembles what is occurring in the quantified-self movement in the health domain. Working to succeed in the indicator game becomes similar to getting a certain amount of exercise per day, eating regularly and the "right food," and checking whether your body weight is on track; it resembles a specific logic of care for one's academic body. Once this care work is broken up into smaller measurable achievements, this provides immediate feedback and reward, and thus creates incentives to stay on track. Yet, this simultaneously has an embedded moral dimension. Indicators seem to offer a way to implicitly hold oneself accountable for continually acting "rationally" in the sense of improving one's standing in terms of indicators. And, it requires us to accept that this new rationality impacts the ways in which we are made sense of by others. By making this analogy with health movements, I want to highlight the fact that narratives about indicators do not simply represent a system on the abstract level. Rather, they form a series of mundane instances in which academics not only narrate about and negotiate for themselves what acting rationally and being accountable to the system means. They also use these instances to tacitly hold each other accountable for contributions and actions within academia.

\section{Concluding Reflections}

The core argument I developed through this short essay is about the need to acknowledge the deep entanglement of temporal structures in academia with indicator systems and to connect this with specific performances of control and power. Reflections on indicators therefore need to go beyond pointing to the limitations of what they can capture, go beyond thinking how we can trick them or find a commonly agreed-upon exception, and instead ask what they are the product of and what they produce. To make visible the temporalities that are embedded in indicators and performed through them allows questioning taken-for-granted assumptions, calling for a retiming of research (Felt et al. 2013) and asking how indicators and academic values can actually relate to each other.

Of course, we all try to find some work-arounds and are clever enough to partially game the system-and we teach our mentees how to do it. Yet, this might not be sufficient in the longterm-both for the system and for the young researchers growing into it. On the contrary, the indicator-driven environments might gain their stability through this form of seemingly "subversive compliance." If we naturalize the production of "short stories" of success and the posing of questions that are answerable in the time of a project's duration, and if we become champions of delivery, we might lose out on imagining and working towards more long-term goals. This might have considerable impact on how larger questions are developed within science, and in particular hinder research that is meant to contribute to addressing the grand challenges of our time.

When talking to researchers, it is clear that multiple competing temporalities definitely lead to a feeling of deep asynchronicity: rhythms of reporting and assessing, of lives and careers in research as well as of project and publication cycles do not necessarily fit together well. This carries, if we draw parallels to studies from other social domains, the danger of a loss of 
attachment and belonging in academic work environments (Müller 2017). In practice, this is counterproductive to the idea of collective knowing and more integrative thinking, which is so heavily emphasized in policy discourse.

Finally, what possible justification is there for developing a densely assessed, indicatordriven academic research system? The ostensible ideal is often the creation of an entrepreneurial university and of a competitive, market-like research system. Yet, observing what actually happens, we see that universities that fully embrace the numbers game run the risk of losing sight of the key aim of discovery, and they become all too concerned with implementing codes, protocols, and guidelines for the documentation, supervision and control of activities. In the end, this might turn universities more into "spiritual replicas of the machinery of the state" (Murphy 2015, 145), from which they initially wanted to break free, rather than leading them to use their autonomy to become strong innovative research institutions, educating the next generation of independent critical thinkers.

\section{Acknowledgements}

This piece is an indirect product of a number of research projects I carried out studying the changing lives in contemporary academic research. I owe a lot to the colleagues who share(d) my passion for this question and to the many debates we had. My particular thanks go to the editors as well as to the reviewer for bringing this collection of articles together, for their constructive criticism and for pushing me to clarify some of my ideas.

\section{Author Biography}

Ulrike Felt is Professor of Science and Technology Studies, Dean of the Faculty of Social Sciences and founding director of the STS Master at the University of Vienna. Her research focuses on governance, democracy and public participation, on shifting research cultures as well as on the role of time and future at the interface of research and society. Her areas of study covered life science and (bio)medicine, nanotechnology and material sciences, new technologies and sustainability research. From 2002-2007 she was editor-in-chief of Science, Technology, \& Human Values. She was one of the editors of the most recent STS Handbook (MIT 2017).

\section{References}

Amaral, A., I. Bleiklie, and C. Musselin, eds. 2008. From Governance to Identity. A Festschrift for Mary Henkel: Springer.

Appadurai, A. 2013. The Future as Cultural Fact. London: Verso.

Bourdieu, P. 1984. Homo Academicus. Paris: Les Editions de Minuit.

Crook, S. 2016. "Lost in CV Limbo." Times Higher Education October 6. Accessed 15 October 2016. http:/ / www.timeshighereducation.com/blog/lost-cv-limbo. 
Espeland, W. N., and M. Sauder. 2007. "Rankings and Reactivity: How Public Measures Recreate Social Worlds." American Journal of Sociology 113 (1): 1-40.

Felt, U., ed. 2009. Knowing and Living in Academic Research. Convergence and Heterogeneity in Research Cultures in the European Context. Prague: Institute of Sociology of the Academy of Sciences of the Czech Republic.

Felt, U. 2016. "Of time-scapes and knowledge-scapes: Re-timing Research and Higher Education." In New Landscapes and Languages in Higher Education, edited by Peter Scott, Jim Gallacher and Gareth Parry. Oxford: Oxford University Press.

Felt, U., D. Barben, A. Irwin, P.-B. Joly, A. Rip, A. Stirling, and T. Stöckelová. 2013. Science in Society: Caring for our futures in turbulent times, Policy Briefing 50. Strasbourg: ESF.

Fochler, M. and S. de Rijcke. 2017. "Implicated in the Indicator Game? An Experimental Debate." Engaging Science, Technology, and Society 3: 21-40. DOI:10.17351/ests2016.xxx.

Fochler, M., U. Felt, and R. Müller. 2016. "Unsustainable Growth, Hyper-competition, and Worth in Life Science Research: Narrowing Evaluative Repertoires in Doctoral and Postdoctoral Scientists' Work and Lives." Minerva 54 (2): 175-200.

Gibbs, P., O.-H. Ylijoki, C. Guzmán-Valenzuela, and R. Barnett, eds. 2015. Universitites in the Flux of Time: An Exploration of Time and Temporality in University Life. London: Routledge.

Klinke, Ia. 2013. "Chronopolitics: A conceptual matrix." Progress in Human Geography 37 (5): 673690. doi: $10.1177 / 0309132512472094$.

Law, J. 2011. "Collateral realities." In The Politics of Knowledge, edited by Fernando Dominguez Rubio and Patrick Baert, 156-178. London: Routledge.

Marres, N. 2012. Material Participation: Technology, the Environment and Everyday Publics: Palgrave Macmillan.

Müller, R. 2012. "Collaborating in Life Science Research Groups: The Question of Authorship." Higher Education Policy 25 (3): 289-311.

Müller, R. 2017. “Crafting a Career in STS: Meaning Making, Assessment, and Interdisciplinary Engagement." Engaging Science, Technology, and Society 3: 84-91 DOI:10.17351/ ests2017.112.

Murphy, P. 2015. "Discovery and delivery: time schemas and the bureaucratic university." In Universitites in the Flux of Time: An Exploration of Time and Temporality in University Life, edited by Paul Gibbs, Oili-Helena Ylijoki, Carolina Guzmán-Valenzuela and Roland Barnett, 137-153. London: Routledge.

Porter, T. M. 1995. Trust in Numbers. The pursuit of objectivity in science and public life. Princeton, NJ: Princeton University Press.

Power, M. 1999. The Audit Society. Rituals of Verification. Oxford: Oxford University Press.

Strathern, M. 2000. "The Tyranny of Transparency." British Educational Research Journal 26 (3): 309321.

Ylijoki, O.-H., and H. Mäntyla. 2003. "Conflicting Time Perspectives in Academic Work." Time $\mathcal{E}$ Society 12 (1): 55-78. 